\title{
FUNCTIONALLY GRADED LATTICE STRUCTURES MADE FROM TITANIUM ALLOY BY SELECTIVE LASER MELTING
}

\author{
aViktoria SOKOLOVA, ${ }^{b}$ Evgenii BORISOV, ' Vadim SUFIIAROV, dAlexey ORLOV, e Igor POLOZOV \\ Peter the Great St. Petersburg Polytechnic University, Saint-Petersburg, Russian Federation \\ a sockolova.vero@ya.ru, ${ }^{b}$ evgenii.borisov@icloud.com, c.vadim.spbstu@yandex.com, \\ dorlov alexey88@mail.ru, eigor.polozov@gmail.com
}

https://doi.org/10.37904/metal.2019.943

\begin{abstract}
This article presents studies of the of lightweight mesh structures properties made by selective laser melting technology. The study of lattice structures with different sizes of struts was made. Also, methods for optimizing grid structures with variable strut sizes were also used. The structure of the mesh elements after hot isostatic pressing and heat treatment was studied. The results of changes in porosity and mechanical properties of lattice structures after hot isostatic pressing and heat treatment as compared with properties of cortical bone are shown. The presented results can be used in the manufacture of medical implants in order to reduce their weight, improve implantation, while ensuring optimal mechanical properties.
\end{abstract}

Keywords: Functionally graded materials, lattice structure, titanium alloy, selective laser melting

\section{INTRODUCTION}

The development trend of materials science and metallurgy, in particular, relates to solving problems of ensuring certain properties of materials not only at the micro level, but also on a macroscopic scale. In connection with the growing requirements for the materials, the task of configuring macroelements has become an particular part of the functional material concept. Lattice and biomorphic structures have become an adequate solution, inspired by natural structures with properties spreaded in volume [1]. The use of gradient designs allows to reduce the mass while maintaining the required mechanical characteristics, and in some cases to increase the rigidity, affect the energy absorption and thermal insulation properties of the object.

One of the possible ways to obtain such materials besides the gas-phase and liquid-phase methods, such as physical gas-phase deposition and film casting, or solid-phase sintering of powders [2,3], accompanied by the formation of randomly organized structures, can be called additive production, which, together with the technology of rapid prototyping not only advance to construct the desired product, but also to test its efficiency under certain conditions within the virtual space. This approach not only reduces the cost of consumed raw materials, but also reduces the period of the object preparation for release. Generative design as a way to create computer models has found application in the creation of medical products, ranging from equipment to prosthetic products with a complex geometry and a certain roughness.

Due to high accuracy and wide combination of technological parameters, the selective laser melting (SLM) method [4] allows to manufacture of porous structures with a complex geometry, but the selection of an effective design and optimization strategy, as well as manufacturing modes, remains a rapidly developing field of research. So, despite the fact that the topological optimization method iteratively improves the layout of the material in a given design space for a given set of loads and boundary conditions, it becomes necessary to take into account the influence of the parameters of the additive process, the material used and its physical properties, warping and shrinkage, the effect of the thickness of the applied layer, the size of the bath of the melt, etc. In addition, the irregular distribution of internal pores in the material obtained as a result of laser fusion can also contribute I contribution to the difference between simulated and empirical data. 
Among the advances in software focused on computer-aided design of computer models of porous structures with different cell sizes and optimization for additive production, Autodesk Within can be noted, with which the authors of this study compared the properties of gradient mesh samples made from computer models, one of which was designed manually, and the other as a result of optimization using the finite element method [5].

\section{MATERIALS AND METHODS}

For the purpose of studying the alloy in a mesh state, the samples presented in the form of $12.5 \times 12.5 \mathrm{x}$ $12.5 \mathrm{~mm}^{3}$, consisted of repeating $5 \times 5 \times 5$ unit cells. Top and bottom parts of parallelepipeds are solid and have $5 \mathrm{~mm}$ height. The device for samples manufacturing is SLM $280 \mathrm{HL}$ machine which principle of operation is based on the obtaining of the required sections on powder bed by laser radiation according the computer model slicing. [6] Samples manufacturing were carried out using the following technological mode: laser power - $250 \mathrm{~W}$, movement speed $-700 \mathrm{~mm} / \mathrm{s}$, distance between individual passes $-120 \mu \mathrm{m}$. The manufacture was carried out from VT6 spherical shape powder (Normin, Russia) with size distribution 14.3 - $70 \mu \mathrm{m}$ (d10-d90). Such alloy is suitable for implantation into living tissue due to its light weight and biocompatibility $[7,8]$. The study of particle morphology and surface condition of the samples was carried out on a scanning electron microscope (SEM) TESCAN Mira 3 LMU.

The basis for studying the grids was assumption that mechanical properties of samples with one rods thickness should increase with rods thickening. Based on this task was set to try to minimize samples weight with safety of these properties. It was assumed that optimization of the grid volume will allow to increase the strength characteristics of the material by reducing the stress-strain state in critical areas. In this connection, the design was projected by automatic and manual methods with the formation of a gradient material.

a)

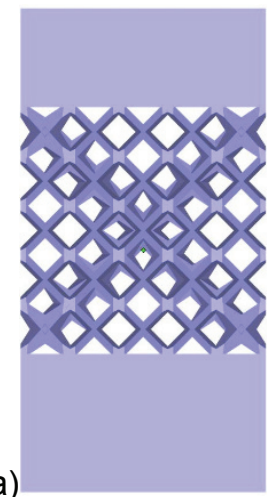

Figure 1 Model of the sample consisted of $\mathrm{N}$ topology unit cells with varying rod thicknesses generated by the manual method: front view (a), side view (b)

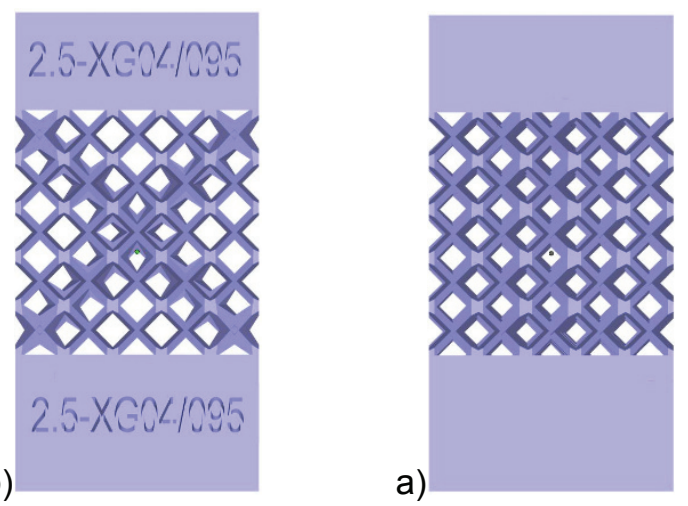

b)

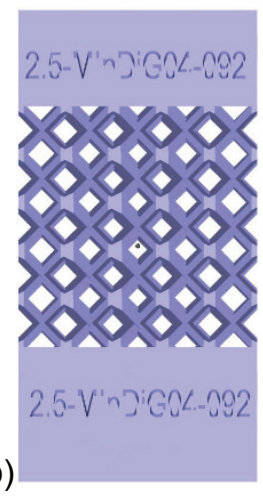

Figure 2 Model of a sample consisted of $\mathrm{N}$ topology unit cells with varying rod thicknesses generated by computer simulation: front view (a), side view (b)

For the study of gradient lattice material behavior two variants of samples with variable rods thicknesses were developed with Within Autodesk software. In the first variant, the gradient grid was generated by manual method (Figure 1). The cells rods forming the main diagonals were increased from $0.4 \mathrm{~mm}$ to $0.95 \mathrm{~mm}$. The thickened cells are arranged so that they form a large $\mathrm{N}$-topology cell inside the sample. Such position was selected based on the results of mechanical tests of lattice structures with different sizes of struts, when in most cases the destruction occurred in the central diagonal section of the mesh cube. In the second variant, the gradient thickness of lattice structure was generated by computer simulation (Figure 2). The initial grid (type N, unit cell size $2.5 \times 2.5 \times 2.5 \mathrm{~mm} 3$ ) with a thickness of 0.4 was calculated and optimized. Before starting the process it was set, as well as the place of its attachment and a load of $150 \mathrm{kN}$. The conditions for the creation of the auto gradient were the input data (material properties, Young's modulus and Poisson coefficient) and boundary conditions 
(maximum stress not exceeding $600 \mathrm{MPa}$ ), allowing to calculate the stress-strain state of the sample and change the geometric dimensions in the structure depending on it. The gradient was changed in increments of $0.01 \mathrm{~mm}$. As a result of the calculation, the thickness of the most loaded rods increased to $0.92 \mathrm{~mm}$, and in the least loaded rods, the thickness remained unchanged, and equal to $0.4 \mathrm{~mm}$.

One of the heat treatment types was annealing in the industrial vacuum furnace MonoTherm (ALD Vacuum Technologies) with maintaining the vacuum level up to $10^{-5} \mathrm{mbar}$. Samples were kept for 2 hours, each regime included cooling in the furnace. The second type was hot isostatic pressure (HIP). Deformations of the samples during compression and tensile testing were carried with materials testing machine Zwick / Roell-Z100.

\section{RESULTS AND DISCUSSION}

\subsection{Microstructure}

SLM process accompanying rapid solidification leads to the the formation of martensite with elongated grains of the primary $\beta$-phase, filled with finely dispersed multi-oriented lamellar $\alpha$-phase. Partial remelting of the previous layer of powder provides epitaxial growth of such grains with parameters of the order of 90-110 $\mu \mathrm{m}$ per 300-900 $\mu \mathrm{m}$, which occurs in the direction of the heat sink along the slope of the grid rods. In compact samples, such grain growth is oriented in the building direction. The microstructure after heat treatment at $920^{\circ} \mathrm{C}$ is a lamellar $\alpha$-phase (white) with a large plate size and a $\beta$-phase (dark) (Figure $\mathbf{3} \mathbf{b}$ ). There is an enlargement of the $\alpha$-phase plates inside as well as along the grain boundaries, which can lead to an increase in plasticity, since the deformation is mainly detected along the grain boundaries. The recrystallization process that has begun has not led to the disappearance of the preferential orientation of the grains; their size after this type of heat treatment is about $150-200 \mu \mathrm{m}$.

a)

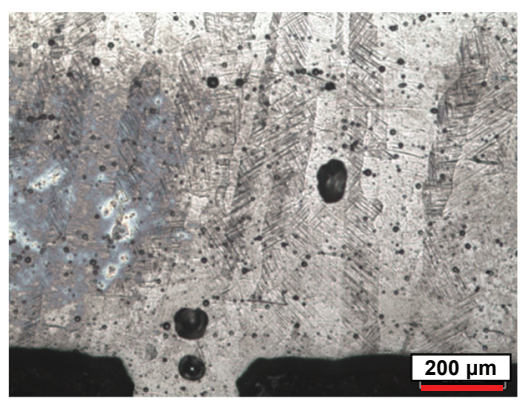

b)

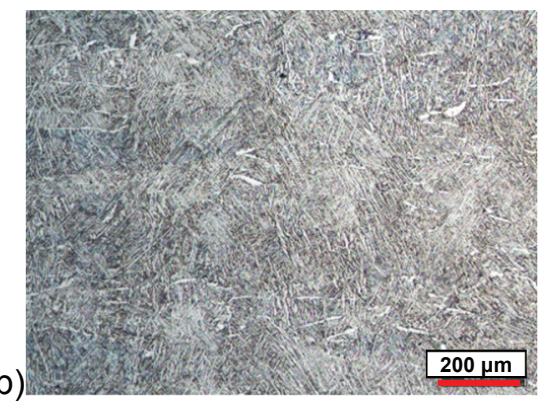

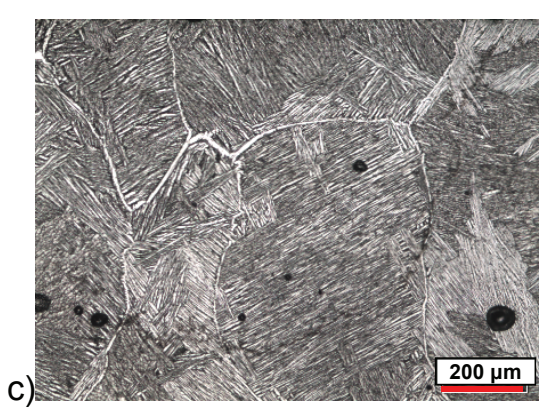

Figure 3 Microstructure of samples with gradient structure (a) without heat treatment, (b) after annealing at $920^{\circ} \mathrm{C}$, (c) after annealing at $1050{ }^{\circ} \mathrm{C}$

After annealing at $1050{ }^{\circ} \mathrm{C}$, large inclusions of $\alpha$-phase and a significant amount of $\beta$-phase are visible at the grain boundaries (Figure $3 \mathbf{c}$ ), which can lead to an increase in plasticity, since the deformation is mainly detected along the grain boundaries. The recrystallization process has led to disappearance of the grains preferential orientation. They have an equiaxial shape and size from 150 to $1500 \mu \mathrm{m}$. Significant heterogeneity may be caused by incomplete recrystallization and coalescence. As heat treatment that minimizes structural defects such as pores was set hot isostatic pressure (HIP) [9] in argon and the pressure was set at $100 \mathrm{MPa}$ for 3 hours at $1050{ }^{\circ} \mathrm{C}$ for each batch. At $920^{\circ} \mathrm{C}$ temperature HIP contributes to formation of a plate a-phase with a significantly larger plate size and $\beta$ phase (Figure 4). There is an increase in the size of the $\alpha$-phase plates inside as well as along the grain boundaries, which can lead to an increase in plasticity, since the deformation is mainly detected along the grain boundaries. Processing at $1050^{\circ} \mathrm{C}$ temperature led to the appearance of an $\alpha$-phase in the form of plates inside the primary $\beta$-grains. Equiaxed $\beta$-grains have sizes of about $60-800 \mu \mathrm{m}$. The orientation of the grains along the cores is absent in contrast to the samples without performing the HIP. 
a)

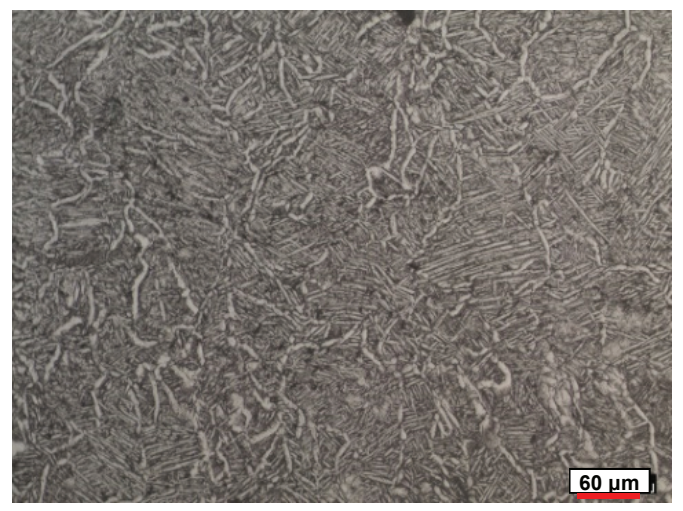

b)

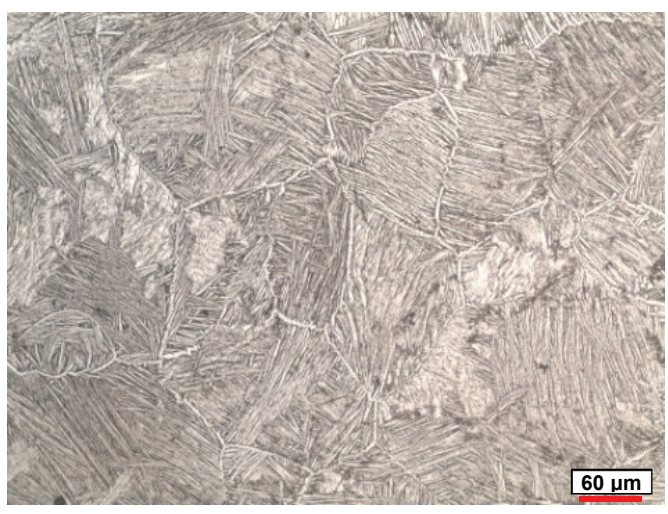

Figure 4 Microstructure of samples with gradient structure after the HIP at (a) $920{ }^{\circ} \mathrm{C}$,

(b) $1050^{\circ} \mathrm{C}$

Hot isostatic pressing contributed to both the structure formation and to closure of pores after the SLM, in contrast to annealing. The values of the residual porosity of the rod material according to the microsections study for the HIP mode at the $1050^{\circ} \mathrm{C}$ temperature is $0.28 \%$, which is $0.37 \%$ less than without additional heat treatment.

\subsection{Mechanical testing}

To assess the mechanical properties of the mesh structures after annealing and hot isostatic pressing at $920^{\circ} \mathrm{C}$ and $1050{ }^{\circ} \mathrm{C}$ on the example of $0.85 \mathrm{~mm}$ grid as the main parameters of mechanical properties after tensile and compression tests, the yield strength that corresponds to the beginning of the rods destruction and the Young modulus were used.

a)

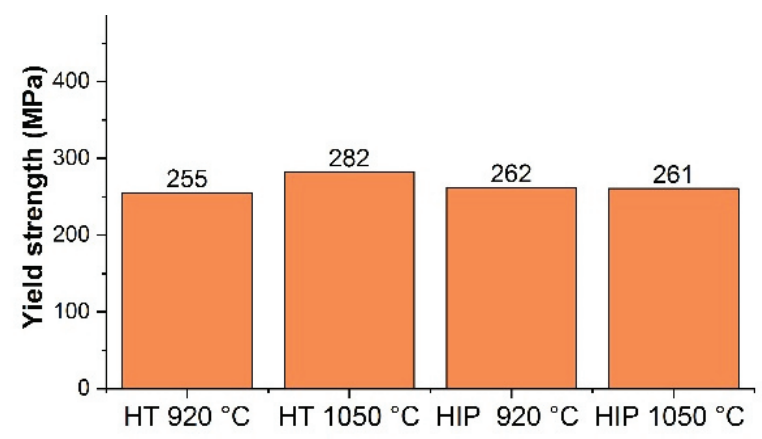

b)

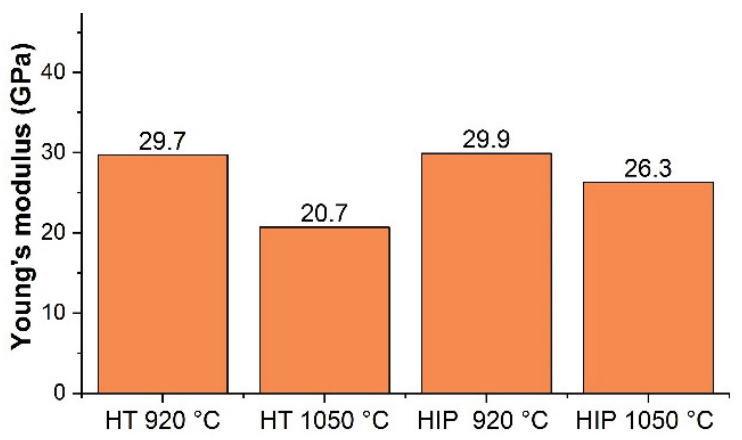

Figure 5 Values of yield strength (a) and Young's modulus (b) for samples with one rods thickness $(0.85 \mathrm{~mm})$ passed tensile testing

As shown on the Figure $\mathbf{5}$ a values of yield strength of HIP processing are almost the same, while differences in temperatures cause more noticeable difference of it. And more active recrystallization process at $1050{ }^{\circ} \mathrm{C}$ promotes decline of Young modulus, because of enlarged grains and smaller movability on their boundaries during deformation. Due to the strength and significant internal stresses of martensite microstructure that leads to brittle destruction samples without post processing weren't tested.

The study of the mechanical characteristics of gradient lattice structure includes tests performed for two gradient types of samples with different rods thicknesses that were obtained with HIP. According to the Figure 6 a the yield strength after compression testing for grids created by computer simulation and the manual method are comparable. This suggests that when compressing, the mesh geometry created by different methods works in the same way, however, differences in geometry affect the values of the Young's modulus 
which for the computer simulation geometry is two times higher than for the created manually. In samples with the computer simulated configuration and the manual configuration and compression tested, the difference between the yield strengths is most significant when tested in compression. It can be assumed that the computer simulated grids is more suitable for use in conditions of tensile forces. This is supported by its higher strength value, which is $66.5 \mathrm{MPa}$ (Figure 7).

a)

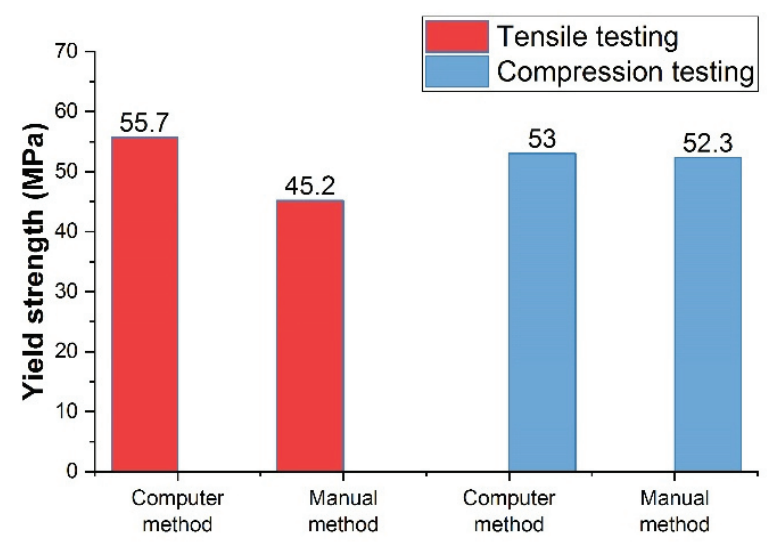

b)

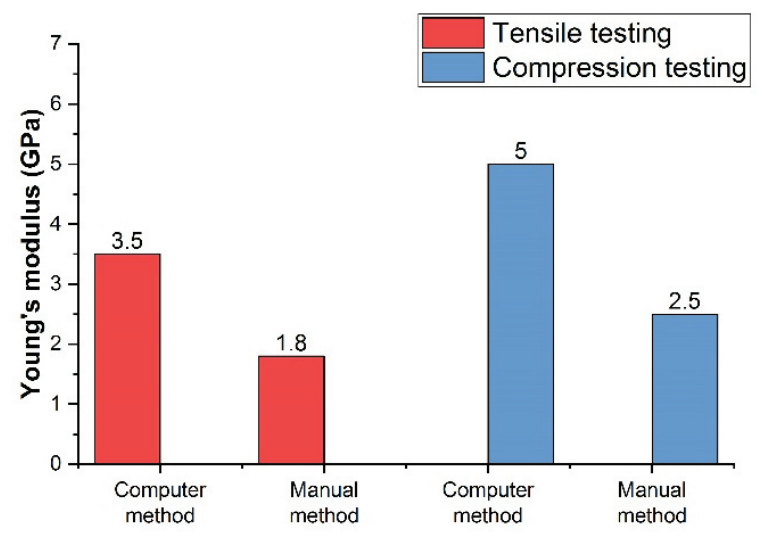

Figure 6 Values of yield strength (a) and Young's modulus (b) for samples with gradient density passed tensile and compression testing with different thickness of rods within the sample, generated by computer simulation and manual method

Such difference is caused by the geometrical features that allow to bear stronger loads, because the nature of the microstructure and the mode of heat treatment are the same and the increase in relative elongation occurs only due to the strengthening of the most loaded elements. The values of Young's modulus for the computer simulated geometry are two times higher than if it created manually as well as in the case of a compression test.

a)

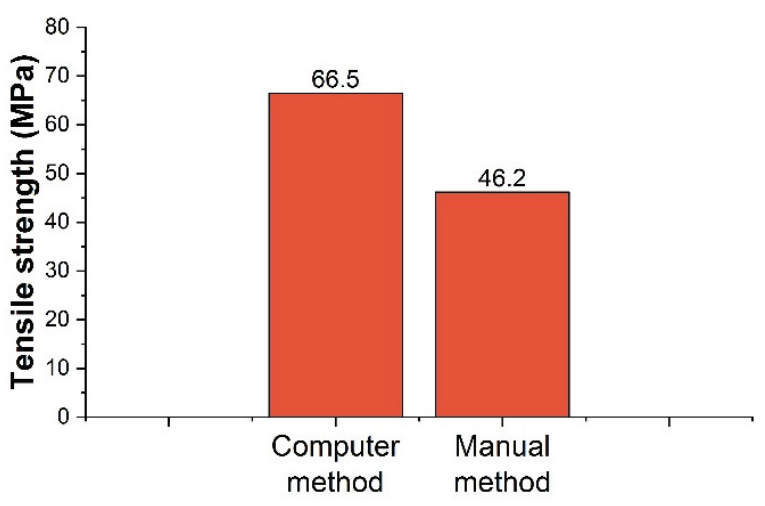

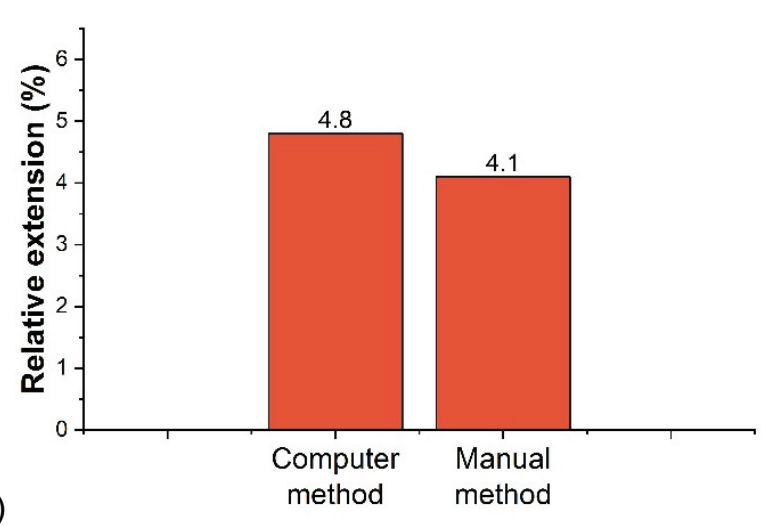

b)

Figure 7 The values of tensile strength (a) and relative extension (b) for samples with gradient cells during tensile testing, generated by computer simulation and manual method

In comparison with the sample of a rod thickness $0.65 \mathrm{~mm}$ (Table 1), which is closest in average thickness to the gradient samples and also passed the HIP processing, higher values of mechanical properties are observed. The same effect is also observed for the grid with a uniform $0.95 \mathrm{~mm}$ rods thickening in the whole volume. Its mechanical properties after the HIP at $920^{\circ} \mathrm{C}$ far exceed the upper limit of the value for the cortical bone and are not suitable for use. 
Table 1 Mechanical properties of functionally graded lattice structures in comparison with regular lattice structures and cortical bone

\begin{tabular}{|c|c|c|c|c|c|c|}
\hline \multirow{2}{*}{ Property } & \multirow{2}{*}{$\begin{array}{l}\text { Post processing } \\
\text { at } 1050^{\circ} \mathrm{C}\end{array}$} & \multirow{2}{*}{$\begin{array}{l}\text { Computer } \\
\text { simulation }\end{array}$} & \multirow{2}{*}{$\begin{array}{l}\text { Manual } \\
\text { method }\end{array}$} & \multicolumn{2}{|c|}{ Rods thickness in grid samples } & \multirow{2}{*}{$\begin{array}{l}\text { Cortical } \\
\text { bone [10] }\end{array}$} \\
\hline & & & & $0.65(\mathrm{~mm})$ & $0.95(\mathrm{~mm})$ & \\
\hline \multirow{2}{*}{$\begin{array}{l}\text { Compression yield } \\
\text { strength (MPa) }\end{array}$} & HIP & 53 & 52 & 138 & 381 & \multirow{2}{*}{$100-230$} \\
\hline & HT & - & - & 126 & 376 & \\
\hline \multirow{2}{*}{$\begin{array}{l}\text { Tensile yield stress } \\
\qquad(\mathrm{MPa})\end{array}$} & HIP & 55.7 & 45.2 & 94.7 & 291.8 & \multirow{2}{*}{$50-150$} \\
\hline & HT & - & - & 61 & 94.5 & \\
\hline \multirow{2}{*}{$\begin{array}{c}\text { Young's modulus } \\
\text { (GPa) }\end{array}$} & HIP & 4.8 & 4.1 & 8.1 & 34.6 & \multirow{2}{*}{$7-30$} \\
\hline & $\mathrm{HT}$ & - & - & 8.8 & 28.3 & \\
\hline
\end{tabular}

It can be assumed that in this case, heat treatment at $1050^{\circ} \mathrm{C}$ without isostatic pressing can be a suitable option, however, such material will be quite tough and this will lead to bone damage. Moreover, the porosity of the structure with such a thickness of rods will be less than that of the gradient sample, which can negatively affect the introduction of living tissue into the implant.

\section{CONCLUSION}

Investigation of lightweight lattice structures with variable rods size generated by computer simulation and manual method and then made by selective laser melting found the difference in the nature of destruction, and mechanical properties. A microstructure with rounded grains was revealed both during annealing and hot isostatic pressing at $920^{\circ} \mathrm{C}$ and $1050^{\circ} \mathrm{C}$, as well as a decrease in the porosity of the rod material in the second type of treatment. It is shown that samples with a certain rod size have higher values of yield strength and Young's modulus than gradient ones. The mechanical properties of the computer gradient turned out to be higher than that of the manually created grid, however, the elimination of shear failure in the latter case is an advantage in the material behavior. In this connection, an increase in insufficient mechanical characteristics due to a change in the gradient modeling strategy in lattice samples will be a possible stage of research on this topic.

\section{ACKNOWLEDGEMENTS}

The work was carried out with the funding from the Federal Target Program «Research and Development in Priority Areas for the Development of the Russian Science and Technology Complex for 2014-2020». The unique identifier of the project RFMEFI57817X0245.

\section{REFERENCES}

[1] LIU, Z., MEYERS, M. A., ZHANG, Z. and RITCHIE, R. O. Functional gradients and heterogeneities in biological materials: Design principles, functions, and bioinspired applications. Progress in Materials Science. 2017. vol. 88, pp. 467-498.

[2] NIINO, M., HIRAI, T. and WATANABE, R., Functionally gradient materials. Journal of the Japan Society for Composite Materials. 1987. vol. 13, no. 6, pp. 257-264.

[3] NEMAT-ALLA, M. M., ATA, M. H., BAYOUMI, M. R. and KHAIR-ELDEEN, WI. Powder metallurgical fabrication and microstructural investigations of aluminum/steel functionally graded material. Materials Sciences and Applications. 2011. vol. 2, no. 12, pp. 1708.

[4] POPOVICH, A., SUFIIAROV, V., POLOZOV, I., BORISOV, E., MASAYLO, D., VOPILOVSKIY, P., SHARONOV,A., TIKHILOV, R., TSYBIN, A., KOVALENKO, A. and BILYK, S. Use of additive techniques for preparing individual components of titanium alloy joint endoprostheses. Biomedical Engineering. 2016. vol. 50, no. 3, pp. 202-205. 
[5] SANTARE, M., LAMBROS, J. Use of graded finite elements to model the behavior of nonhomogeneous materials transactions-american society of mechanical engineers journal of applied mechanics. 2000. vol. 67, no 4. pp. 819822.

[6] YAP, C. Y., CHUA C. K., DONG, Z., LIU, Z., ZHANG, D. Q., LOH, L. and SING, S. L., Review of selective laser melting: Materials and applications. Applied Physics Reviews. 2015. vol. 2, no 4. 041101.

[7] MURR, L., QUINONES, S., GAYTAN, S., LOPEZ, M. I., RODELA, A., MARTINEZ, E., HERNÁNDEZ, D., MARTINEZ, Edwin, MEDINA, Frank and WICKER, Ryan. Microstructure and mechanical behavior of Ti-6Al-4V produced by rapid-layer manufacturing, for biomedical applications Journal of the Mechanical Behavior of Biomedical Materials. 2009. vol. 2, no. 1. pp. 20-32.

[8] POPOVICH,A., SUFIIAROV,V., POLOZOV, I., BORISOV, E., MASAYLO,D. and ORLOV, A. Microstructure and mechanical properties of Ti-6Al-4V manufactured by SLM. Key Engineering Materials. 2015. vol. 651-653, pp. 677682.

[9] DADBAKHSH, S. and HAO, L. Effect of hot isostatic pressing (HIP) on Al composite parts made from laser consolidated $\mathrm{Al} / \mathrm{Fe}_{2} \mathrm{O}_{3}$ powder mixtures. Journal of Materials Processing Technology. 2012. vol. 212, no. 11, pp. 2474-2483.

[10] VAN BAEL, S., CHAI, Y. C., TRUSCELLO, S., MOESEN, M., KERCKHOFS, G., VAN OOSTERWYCK, H. and SCHROOTEN, J. The effect of pore geometry on the in vitro biological behavior of human periosteum-derived cells seeded on selective laser-melted Ti6Al4V bone scaffolds. Acta Biomaterialia. 2012. vol. 8, no. 7, pp. 2824-2834. 